\title{
RESEARCHING HUMAN EXPERIENCE: VIDEO INTERVENTION/PREVENTION ASSESSMENT (VIA)
}

\author{
Jennifer Patashnick \\ Michael Rich \\ Video Intervention/Prevention Assessment (VIA) \\ Children's Hospital Boston \\ 300 Longwood Avenue \\ Boston, Massachusetts 02115 \\ Email: jennifer.patashnick@childrens.harvard.edu
}

\begin{abstract}
Human experience is a critical subject for research. By discussing Video Intervention/Prevention Assessment (VIA), a patient-centered health research method where patients teach their clinicians about living with a chronic condition through the creation of visual illness narratives, this paper examines the value of qualitative inquiry and why human experience rarely is investigated directly. An analysis of a sample VIA data is presented to demonstrate how, by utilizing grounded theory and qualitative analysis, one can derive rich and unique information from human experience.
\end{abstract}

\section{INTRODUCTION}

Human lives are continuous streams of experience. At every moment of every day, our senses are bombarded by a variety of stimuli. We synthesize experience by filtering and selecting stimuli of importance, then organizing those perceptions into concepts that can be related to others and on which we can act. As infants, our experiences fundamentally alter and shape our brains into an architecture that can interact effectively with the environments that influence their development. Experience is the basis of learning; synthesizing and communicating experience is the basis of teaching.

Historically, all information was communicated through the use of stories, transmitting knowledge from person to person and from one generation to the next. We understood and trusted narrative as a means of conveying important data to each other. However, with the development of the scientific method and the Descartian view of the world, we became enamored with our ability to measure, quantify, and be "precise." We came to the belief that to be truly scientific, information had to be numerical. Positivism regards only what is quantifiable to be of scientific value (Comte 1851/1865). If one cannot assign a numerical value to an observation, one should not attempt analysis because non-numerical data cannot be manipulated and compared. Without a standard value against which to compare, measurement is imprecise and the validity of the observation is questionable. So how does one investigate and analyze life experience in a way that is not only useful but also scientifically valid?

In striving to be evidence-based, medicine often leans toward a positivist evaluation of outcomes. While the number of hospital admissions or total cost of antibiotic therapy can be useful for evaluating effectiveness of health care delivery or for standardizing treatment, it does not address the core issues of illness, health, and health care. Because issues such as quality of life or why patients do not adhere to medical plans are difficult to measure, much of the scientific community has agreed that translating experience into such quantifiable factors is the best means of evaluating health and health care. This approach is indirect and the outcomes are selected as much for their measurability as for their salience. 


\section{EXPERIENCE AS DATA}

A frequent concern about the analysis of human experience using narrative is reliability of recall. Studies have shown that individuals asked to provide details about certain events, such as what they ate that day, do not exhibit perfect recall nor report everything they consumed (Armstrong et al. 2000). However, what individuals do remember is that which is the most salient for them about the experience (Fries et al. 1995). In medicine, it is the patient's experience, understanding, and beliefs about the origins and meaning of illness that most strongly determine his/her response to illness and adherence to medical plans (Rich et al. 2002). Yet only recently have questions in the biomedical realm been approached with narrative research methods, and this work is far from universally accepted or encouraged.

Another reason for this lack of acceptance may be the time required for each patient to present his/her own individual perspective on the illness to the clinician. However, by understanding the emotional and psychological components of the patient's life experience and considering them in developing the treatment plan, the clinician may be able to more effectively address how the patient's life affects the patient's illness and improve his/her prognosis. The distinction between disease and illness is a crucial one. Disease, in this case, can be defined as the biological dysfunction that caused the patient to seek medical care (Kleinman 1988, Morse \& Johnson 1991). Illness is how the patient experiences disease in the context of his/her own life (Rich et al. 2000c). Three patients with identical disease states (as measured using universally accepted clinical criteria) might experience three distinct illnesses, with differing symptomatology, levels of disability, and quality of life. A considerable amount of research on the mind-body connection indicates that one's mental state can dramatically affect one's health (Melmed 2001). So why is the patient's experience of illness so frequently ignored?

For some, the use of human experience as data may challenge the perception of the objectivity of medical diagnosis. Using evidence based medicine, doctors base treatment plans on neutral "scientific" data (Rosenberg \& Donald 1995). In Western medicine, recording measurable data, such as a patient's heart rate, blood pressure, and temperature, is a staple of clinical assessment. Clinicians rely on these measurements to determine a patient's health status in comparison to known healthy values. An abnormally elevated temperature can indicate the presence of an infection. Increased temperature is a sign of disease, a relatively predictable, common response of human physiology. Psychological response to illness, however, can have a profound effect on one's perception of health, one's response to disease, and one's ultimate outcome. These responses are individual, unpredictable, and cannot be quantified as easily as body temperature. In order to understand a patient's illness, a clinician must learn from the patient what $\mathrm{s} /$ he experiences, what meaning $\mathrm{s} / \mathrm{he}$ has made from that experience, and what significance $\mathrm{s} / \mathrm{he}$ has assigned to the experience. By inviting the patient into a health care partnership, the clinician and patient together can target treatment strategies to address the features of the illness most important to the patient and develop a medical management plan to which the patient is motivated to adhere.

Patients' experiences of their health and illness introduce subjectivity to the medical evaluation, which is difficult to measure. One way to investigate experience is to collect as many data as possible from the constant stimuli of sights and sounds to which an individual is exposed, while simultaneously providing the individual with an opportunity to narrate the scene. The documentation of stimuli preserves the experience for later reflection and analysis, while the accompanying narration allows the incorporation of the individual's subjective, first-person point of view. Then, an analytical strategy for assigning importance to the stimuli and narrative must be developed.

Traditional scientific and biomedical protocol would suggest that one start counting events and 
assigning numbers to quantify data. Indeed, Video Intervention/Prevention Assessment (VIA) data include quantifiable information such as individual demographics or numbers of observed events. However, none of these measurements effectively relate the illness experiences or the individuals' responses to those experiences. Testable hypotheses about much of this quantitative data can be developed before the study begins. In contrast to traditional hypothesis-driven research, grounded theory seeks to collect and organize data until a theory emerges, constantly testing and modifying the theory to fit the data. Grounded theory allows researchers to collect a broad range of data, discovering critical information for which they did not go looking. In this way, the researcher need not predict what might be found by a specific line of inquiry, but can let the data "speak for itself" (Glaser 1992, Glaser \& Strauss 1967, Strauss \& Corbin 1990).

\section{THE VIA METHOD}

Allowing subjects to represent and document themselves and their experiences is not a new idea in academia. Numerous studies in a multitude of disciplines including anthropology (Worth \& Adair 1997), psychology (Furman 1990), and education (Urban 1989) have demonstrated the value of the individual's own perspective on their lives. When patients at Children's Hospital Boston are enrolled in VIA, they are asked to "teach your doctor" what it is like to live with a chronic condition. VIA seeks to improve the heath care of chronically ill patients by more actively including the patient's life experience in his/her treatment. With the elimination of house calls, clinicians are no longer seeing patients in the context of their everyday lives. Further, since limits are imposed upon clinical visits by insurance companies and other external forces, actual time spent with each patient has been reduced in some cases to mere minutes.

\section{Data collection}

VIA was started in 1994 at Children's Hospital Boston by Michael Rich, MD, MPH in response to what was perceived to be an ever-increasing gap in communication between clinicians and their patients, particularly children and adolescents (Rich \& Chalfen 1999, Rich et al. 2000b). VIA bridges this void by loaning participants video camcorders and encouraging them to record anything and everything they feel is pertinent to their lives with their condition, particularly those factors about which doctors may not ask or be aware. After informed consent is obtained, VIA participants are loaned lightweight, handheld camcorders, given access to an unlimited supply of blank tape, and encouraged to videotape as much as possible over the course of several months. In this way, large quantities of data may be accrued. A joint decision between the participant and a VIA researcher determines when the participant's visual narrative has been completed. Some participants have collected only a few hours of videotape; others' visual narratives constitute several days' running time. Nearly all is valuable for its unique ability to convey the participant's view of his or her life. However, none of it can be analyzed effectively using quantitative methods.

Once a participant has completed his/her visual narrative, it is logged in detail. These logs are used as guidebooks to the data, so that a multidisciplinary team of physicians, anthropologists, social workers, and psychologists can review any or all of the audiovisual data for information salient to the study being conducted. This yields a multidimensional perspective on living with a chronic condition in the context of the patient's own life. As an example, consider the following scene:

JS, an 18 year old male with sickle cell disease, is talking with his friend Jerry in a bathroom. JS, clearly inebriated, is drinking beer and smoking a cigarette while he discusses his initial experiences with alcohol and tobacco. Jerry is skeptical of JS's claim that he could quit smoking and drinking at any time. JS then says he could quit, but doesn't 
want to. Jerry tells JS that he should stop because of his sickle cell disease. JS resents this, curses sickle cell, and says, "I want to live my life like I never had sickle cell." JS suggests that if he didn't have sickle cell disease, then he wouldn't drink or smoke so much, while Jerry predicts JS would drink even more.

Although the scene is only three minutes long, it contains many distinct themes and layers of meaning. The complexity and density of important information in these visual illness narratives are what led the VIA research team to turn to computer-assisted qualitative analysis. The pilot VIA project on asthma (Rich et al. 2000a) was originally analyzed on paper. However, as sophisticated software was developed for qualitative analysis, we explored the use of several programs to determine which could facilitate our process most readily. The analysis which can be done on a computer is much more comprehensive than that which can be performed manually, but many qualitative analysis programs are ill-equipped for what we wished to accomplish: a more complete and textured understanding of patient experience. Previous studies using audiovisual material analyzed brief, "micro" sequences of human behavior where each frame of video was of interest and predictable events, such as a child kicking a ball in a playground, could be quantified (Tronick et al. 1991). VIA, however, is concerned with "macro" features of human experience that could not be predicted and needed to be elicited from hundreds of hours of visual narrative that participants collected. VIA is less interested in how many times the child kicks the ball than it is in why the child is at the playground, what he does, how he interacts with other children, and if and how the child's medical condition affects these behaviors.

The quantity of videotape collected represented a significant data management challenge. Additionally, the density and complexity of detail in the audiovisual data allowed for significant nuance of meaning, with overlapping layers of events, personalities, and emotions present in each scene. Each observer of human behavior, on tape or otherwise, has their own interpretation of the event, the primary criticism of those who question the validity of this type of research. Of paramount concern was standardization and reproducibility of VIA analysis, particularly in the initial stages of analysis. This intricate combination of factors caused the VIA research team to develop an unprecedented analytical method using text logs and NVivo (1998).

Because no current qualitative analysis software program can directly handle the quantities of audiovisual data collected by VIA easily and flexibly without requiring immense computer resources, VIA visual narratives are "transcribed" into logs, text intermediates which function as a "road map" of the video data. The creation of the log is a detailed process. Since a picture really is "worth a thousand words", the logs must convey in text the content of the visual narrative without losing the richness and dimensionality of the original video.

The VIA research team realized that there are two simultaneous streams of information in all audiovisual scenes: objective and subjective. Loggers are trained to readily identify and document each in a specific text format. Objective elements are those which are directly observable and emotionally neutral, descriptions that could be generated by and agreed upon by any observer. Returning to the scene previously described, an example of objective data is the observation that JS is holding a bottle and leaning against a door. In the development of the logging process, the VIA research team had multiple loggers review the same tapes, and had each logger "transcribe" the tapes several times. Little variation was found between the logs, particularly in the case of the objective observations. Therefore, VIA has both synchronic and diachronic reliability.

Subjective data are elements such as the emotional tone or content of the scene and may vary based on how much of the context is known by the observer, how the observer relates to those in the scene, and even the age and gender of the observer. In our example scene, the logger subjectively notes that Jerry seems to be acting as JS's conscience "like Jiminy Cricket [from the animated film of Pinocchio]". This analogy, as descriptive and apt as it was, may or may not have occurred to a 
different observer. Each logger's subjective observations serve to further describe the emotional tone and enhance the psychological elements of the narratives. Figure 1 shows the completed log of the example scene. Note that objective observations appear in normal text, while subjective observations are in italics. (For further details of the logging procedure, please refer to Rich \& Patashnick 2002.)

\section{4:01/00:31:21}

Jerry films JS, who is leaning against the wall in a bathroom, holding and drinking from a bottle of beer. Jerry says, "You see what JS's got in his hand... a man with sickle cell drinking that shit." JS says "I've been doing this since I was...how old was I?" Jerry says "I don't know, but I think you're a little drunk." JS says that he was twelve years old when he first had alcohol and that he didn't like it. Jerry asks, "Why'd you do it?" JS responds “Just to try it. And I ended up throwing up." JS adds it wasn't peer pressure that convinced him to try drinking.

He doesn't let others pressure him into things, but he ends up participating anyway maybe to add excitement to his life?

\section{4:01/00:32:08}

Jerry asks if JS would make the same decisions about alcohol if he could go back in time. JS says no. Jerry asks the same question about cigarettes and JS says "No, hell no!" JS smokes a cigarette during this conversation and says he is addicted.

He seems to be aware that these substances are bad for his health and doesn't want to have these habits, straightforwardly admitting regret. His friend Jerry seems insightful, and acts like JS's conscience, almost like Jiminy Cricket!

\section{4:01/00:32:38}

Jerry suggests that there are nicorette patches and JS says that if he wanted to quit, he could quit. Jerry says, "No you couldn't...that's bullshit." JS says if he really wanted to, he thinks he could quit cold turkey, but he just doesn't want to. JS says "I don't want to quit cigarettes and I don't want to quit drinking and $f^{* * * * * *}$ smoking weed." Jerry says "But you should though, that's the whole point." JS interrupts Jerry and says, "Why? Why why why? Because I got sickle cell?" Jerry responds "exactly."

Very clear from JS's tone that he resents sickle cell ruling his life.

\section{4:01/00:33:25}

JS continues in a raised voice "No, but the thing is, just "cause I have sickle cell, I want to live my life like I never had sickle cell." Jerry says, "That's just it... because you have sickle cell, you've got to do different things."

\section{4:01/00:33:35}

JS waves his middle finger to the camera and says "F*** sickle cell!" He laughs. Jerry says "That's too bad because it's flowing through your bloodstream right now."

\section{4:01/00:33:43}

JS continues "I don't know; that's the problem. I got sickle cell. You know, that's it. That's what pisses me off. That's the whole fact of the whole shit is I got sickle cell. That's it. That's it. If I didn't have sickle cell, do you think l'd be doing this? Maybe. Maybe not." Jerry responds "Actually, I think if you didn't have sickle cell you'd have one in that hand and one in that hand right there," as he films the bottle of beer JS is holding.

Figure 1: Example scene logged in VIA format

\section{Data analysis}

Once the $\log$ of the visual narrative is created, it is imported into NVivo, a software program designed by QSR for the management, analysis, and structuring of qualitative data. NVivo allows VIA researchers to draw meaning from the vast quantity of visual narratives through coding. Following the edicts of grounded theory, coding starts with a clean slate where no themes are anticipated or predicted from the data in advance. Any theme which emerges from a review of the $\log$ can be assigned to a node. Nodes are labels for all data which share a common theme or code. For our purposes, a node can contain pieces of data that are as short as a single word or as long as several pages of text, encompassing any time interval of the original video from a frame to the length of the tape. Each passage of text, analyzed from various perspectives, can be assigned to an 
infinite number of distinct nodes which can seamlessly overlap.

A selection of codes for the example scene are presented in Figure 2 as coding stripes. The stripes show which sections of the log have been labeled with various codes.

\section{4:01/00:31:21 \\ Jerry films JS, who is leaning against the wall in a bathroom, drinking a beer. Jerry says, "You see what JS's got in his hand... a man with sickle cell drinking that shit." JS says "I've been doing this since I was... how old was I?" Jerry says "I don't know, but I think you're a little drunk." JS says that he was twelve years old when he first had alcohol and that he didn't like it. Jerry asks. "Why'd you do it?" JS responds "Just to try it. And I ended up throwing up." JS adds it wasn't peer pressure that convinced him to try drinking. \\ He doesnt let others pressure him into things, but he ends up participating anyway maybe to add excitement to his life?}

\section{4:01/00:32:08}

Jerry asks if JS would make the same decisions about alcohol if he could go back in time. JS says no. Jerry asks the same question about cigarettes and JS says "No, hell no!" JS smokes a cigarette during this conversation and says he is addicted.

He seems to be aware that these substances are bad for his health and doesnt want to have these habits, straightfonvardly admitting regret. His friend Jerry seems insightful, and acts like JS's conscience, almost like Jiminy Cricket!

Jerry suggests that there are nicorette patches and JS says that if he wanted to quit, he could quit Jerry says, "No you couldn't that's bullshit." JS says if he really wanted to he thinks he could quit cold turkey, but he just doesn't want to. JS says "I don't want to quit cigarettes and I don't want to quit drinking and $f$ smoking weed." Jerry says "But you should though, that's the whole point." JS interrupts Jerry and says, "Why? Why why why? Because I got sickle cell?" Jerry responds "exactly."

Very clear from JS's tone that he resents sickle cell ruling his life.

04:01/00:33:25

JS continues in a raised voice "No, but the thing is, just "cause I have sickle cell, I want to live my life like I never had sickle cell." Jerry says, "That's just it... because you have sickle cell, you've got to do different things.

\section{4:01/00:33:35} says "That's too bad because it's flowing through your bloodstream right now.

\section{4:01/00:33:43}

JS continues "I don't know; that's the problem. I got sickle cell. You know, that's it. That's it. That's it. If I didn't have sickle cell, do you think l'd be doing this? Maybe.

\section{4:01/00:32:38}

JS waves his middle finger to the camera and says " $F \quad$ sickle cell!" He laughs. Jerry That's what pisses me off. That's the whole fact of the whole shit is I got sickle cell. Maybe not." Jerry responds "Actually, I think if you didn't have sickle cell you'd have one

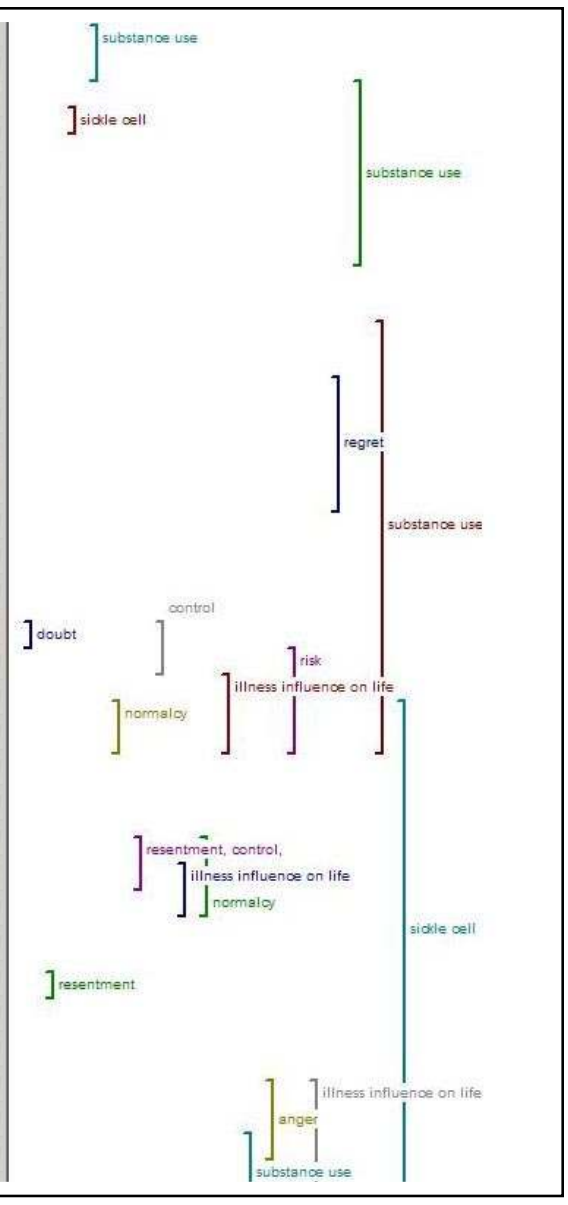

Figure 2: Logged scene with NVivo coding stripes

NVivo keeps track of the nodes as they are created in a list format. As each participant's log is coded, the list of nodes expands. This growth is rapid at the start of coding and tapers off throughout the process as codes that characterize the patients' experiences are defined and standardized. At the conclusion of coding (or several coding passes as necessary), more complex questions can be asked of the coded data. For example, one could ask in what ways participants tried to normalize their illness experience. To do this, one would create a query that would identify all the passages of the logs where a specific reference to an illness and a code of "normalcy" occurred concurrently, as they do in Figure 2. One may be looking for the answers to any or all of the following questions: Is JS the only participant who seeks to normalize his illness through his risk-taking? In what other "typical" adolescent behaviors do adolescents with chronic illness choose to engage? If one were to analyze these same data by hand, each question would cause the 
researcher to have to re-watch hundreds of hours of video or re-read thousands of pages of logs. Instead, NVivo keeps track of all codes, and one needs only to ask the questions of the data to be presented with examples that fit the search criteria.

This is not to say that using qualitative software is without challenge or that the computer does the thinking for the researcher. Certainly, one needs to employ appropriate strategies when querying the data to avoid nonsensical search results. Simply put, one must know what one is asking. Codes must be consistently applied and defined, and searches carefully constructed. For verification of a code, the VIA research team can go back to the original visual narrative at any time, and view the sections they are coding to gain even more context from the scene to confirm the applicability of a particular code. NVivo allows researchers easy, direct access to the original audiovisual data through the use of DataBites linked to sections of video that can be embedded in the appropriate sections of the $\log$ document.

\section{THE UBIQUITY OF EXPERIENCE AND THE VALUE OF VIA}

To date, VIA has focused solely on medical conditions in pediatric, adolescent, and young adult populations, but the versatility of the VIA method allows the application of the technique to virtually any human condition. VIA has the potential to explore social issues such as violence, teen pregnancy, or homelessness and life events such as the college experience. With widespread use of video cameras by the general public for the creation of home movies, and the increase of so-called "reality" television shows, one might question why what VIA is doing is considered so distinctive.

First, what sets VIA apart is the intent of each project and the motivation of the participants. The goal is for clinicians to gain a better understanding of their patients' lives with chronic conditions. In the traditional doctor-patient interaction, doctors hold the position of power. Yet, it is only when patients take ownership of their condition and their day-to-day medical management that their health can improve. By asking patients to teach doctors about a health condition and giving them a camcorder, the power shifts quite literally into the hands of the patients, the true "experts" on their own lives. The knowledge and experience that the patient contributes will help clinicians to partner effectively with their patients by communicating with them as equals to create treatment plans with which both parties are comfortable and to which both are committed.

Second, most "home movies" are created because of an event such as a birthday party, graduation, or vacation. Since these events do not happen every day, people consider these occurrences "special" and, therefore, worth capturing on tape, while the rest of their days generally happen without a thought toward documentation. Even "reality" television programs rarely show everyday events for their own sake. Instead, they focus on a constructed quest, conflict, or dare, something considered "dramatic" enough to be "worth taping". For VIA, every moment counts. One of the biggest challenges the VIA Field Coordinator faces is how to shatter the participants' expectations of an "MTV view of the world." She must remind participants that their view of their lives is more interesting than attention-grabbing, artistic shots, and reinforce VIA's perspective that no part of their life is "boring." Even what they may think is dull or routine is of value to our research. We really do want to see how they live their everyday lives, and that includes getting up in the morning, eating breakfast, brushing their teeth, going to school or work, relaxing, participating in sports, surfing the web, taking medications, going to doctors' appointments, and all other parts of their day, regardless of whether they are ordinary or extraordinary.

Third, with VIA, participants are in complete control of what they choose to record. Participant control of the camera lends a subjective, first person viewpoint on their lives, which is crucial to understanding the how the participant perceives and lives within his/her life context. In home movies, "reality" television, and even documentaries, it is usually an uninvolved third person who 
decides what, how, and when to record. This fundamentally changes the nature of the data collected, since the gaze of the camera observing an event from the outside can not only influence the event, but has a different perspective on the outcome. VIA gives all control and decision-making power to participants, asking them to show clinicians how they live, what they need, and what their priorities are. This perspective allows clinicians to approach the situation through the patient's eyes, instead of relying on what the clinician might hypothesize or expect the patient would want or need.

\section{CONCLUSION}

VIA, when used in conjunction with NVivo, applies media and information technology toward a scientifically rigorous investigation of human experience. The development of inexpensive, lightweight consumer electronics combined with the increasing flexibility and user-friendliness of qualitative analysis software programs has created the opportunity to return control of many aspects of health to the real experts on medical conditions - individuals who live with illness on a daily basis. Although traditionally understood as a weakness, VIA makes the subjective view of the participant into one of the greatest strengths of the data. By asking participants to draw on their experience and teach their clinicians what is salient to them about their illnesses, VIA shows clinicians what the patient sees as most important to the healing process. Human experience is a universal but frequently overlooked source of data on health and illness because it is perceived as difficult to measure. However, when examined with VIA's rigorous analytic method based on grounded theory and qualitative analysis, these complex data can reveal aspects of the patient's illness experience of which clinicians were not previously aware. The experience and understanding of the patient can be coupled with the knowledge and skills of the clinician allowing them to become equal partners in more effective and humane health care delivery.

\section{REFERENCES}

Armstrong, A., MacDonald, A., Booth, I.W., Platts, R.G., Knibb, R.C., \& Booth, D.A. (2000) Errors in memory for dietary intake and their reduction. Applied Cognitive Psychology, 14(2), 183191.

Comte, A. (1865) A general view of positivism (J.H. Bridges, Trans.). London: Trübner and co. (Original work published 1851).

Fries, E., Green, P., \& Bowen, D. J. (1995) What did I eat yesterday? Determinants of accuracy in 24-hour food memories. Applied Cognitive Psychology, 9(2), 143-155.

Furman, L. (1990) Video therapy: An alternative for the treatment of adolescents. Arts in Psychotherapy, 17(2), 165-169.

Glaser, B. G. (1992) Basics of grounded theory analysis. Mill Valley, CA: Sociology Press.

Glaser, B. G. \& Strauss, A. L. (1967) The discovery of grounded theory. Chicago: Aldine.

Kleinman, A. (1998) The illness narratives: suffering, healing, and the human condition. New York: Basic Books.

Melmed, R. (2001) Mind, body, and medicine: an integrative text. New York: Oxford University Press.

Morse, J. M., \& Johnson, J. L. (1991) The illness experience: dimensions of suffering. Newbury Park, CA: Sage Publications.

NVivo (Version 2.0) (1998) [Computer software]. Victoria, Australia: Qualitative Solutions and Research.

Rich, M., \& Chalfen, R. (1999) Showing and telling asthma: Children teaching physicians with visual narratives. Visual Sociology, 14, 51-71. 
Rich, M., Lamola, S., Amory, C., \& Schneider, L. (2000a) Asthma in life context: Video Intervention/Prevention Assessment (VIA). Pediatrics, 105(3), 469-477.

Rich, M., Lamola, S., Gordon, J., \& Chalfen, R. (2000b) Video Intervention/Prevention Assessment: A patient-centered methodology for understanding the adolescent illness experience. Journal of Adolescent Health, 27(3), 155-165.

Rich, M., \& Patashnick, J. (2002) Narrative research with audiovisual data: Video Intervention/Prevention Assessment (VIA) and NVivo. International Journal of Social Research Methodology, 5(3), 245-261.

Rich, M., Patashnick, J., \& Chalfen, R. (2002) Visual illness narratives of asthma: Explanatory models and health-related behavior. American Journal of Health Behavior, 26(6), 442-453.

Rich, M., Taylor, S.A., \& Chalfen, R. (2000c) Illness as a social construct: Understanding what asthma means to the patient to treat the disease. The Joint Commission Journal on Quality Improvement, 26(5), 244-253.

Rosenberg, W., \& Donald, A. (1995) Evidence based medicine: an approach to clinical problemsolving. British Medical Journal 310, 1122-1126.

Strauss, A., \& Corbin, J. (1990) Basics of qualitative research: grounded theory procedures and techniques. Newbury Park, CA: Sage Publications.

Tronick, E., Beehly, M., Fetters, L., \& Weinberg, M. K. (1991) New methodologies for evaluating residual brain damage in infants exposed to drugs of abuse: objective methods for describing movement, facial expressions, and communicative behaviors. Methodological issues in controlled studies of prenatal exposure to drugs of abuse. National Institute of Drug Abuse Research Monograph (114, pp. 262-291). Washington, DC: Department of Health and Human Services.

Urban, M. (1989) Video biographies: Reading, researching, and recording. English Journal, 78(8), 58-59.

Worth, S., \& Adair, J. (1997) Through Navajo eyes: An exploration in film communication and anthropology. Albuquerque: University of New Mexico Press.

\section{ACKNOWLEDGEMENTS}

The authors wish to thank the organizations that have supported VIA, including the National Institute of Child Health and Human Development, the researchers and interns who have left their imprint on VIA, and especially each VIA participant who has made VIA what it is by so graciously sharing his or her life with us.

\section{COPYRIGHT}

Jennifer Patashnick and Michael Rich (C) 2004. The authors assign Griffith University a nonexclusive license to use this document for personal use provided that the article is used in full and this copyright statement is reproduced. The authors also grant a non-exclusive license to Griffith University to publish this document in full in the Conference Proceedings. Such documents may be published on the World Wide Web, CD-ROM, in printed form, and on mirror sites on the World Wide Web. Any other usage is prohibited without the express permission of the authors. 